\title{
LITERATURA E INSTITUIÇÃO
}

\author{
Rosa Maria Olher \\ Doutoranda em Estudos da Tradução - UNICAMP \\ Professora do Depto de Letras - UEM
}

Resumo: Este artigo tem como objetivo trazer à tona algumas discussões relacionadas a conceitos ou juízos de valor do que seja "literatura". Partindo de uma visão pós-moderna de críticos literários e filósofos como Terry Eagleton e Jacques Derrida, este trabalho não pretende chegar a uma definição precisa ou a um "suposto" conceito, mas sim problematizar e levantar questões que sejam pertinentes e importantes para a reflexão daqueles que trabalham com literatura, seja ela brasileira ou estrangeira, bem como para os teóricos e críticos literários, que através de suas práticas e visões, contribuem, por um lado, para o continuísmo das idéias prescritivas e pré-concebidas e, impedem, por outro, o lugar de um pensar diferenciado e mais crítico de valores institucionalizados ou estabelecidos.

Palavras-chave: Literatura; Texto Literário; Valores; Instituição.

Abstract: The aim of this paper is to discuss concepts and beliefs about what is understood by "literature". Based, at first, on post-modern views of some literary critics and philosophers such as: Terry Eagleton and Jacques Derrida, this work does not intend to define literature precisely, but, mainly, put in doubt or raise questions which are highly relevant to the reflection of the professionals who work with Brazilian and Foreign Literature, as well as for the theoreticians and literary critics, who contribute to the continuity of prescriptive and pre-conceived thoughts and, at the same time, restrain the thinking of a different and more critical view of institutionalized, established values.

Keywords: Literature; Literary Text; Values; Institution. 


\section{Introdução}

Muitas têm sido as perguntas relacionadas à literatura, porém, suas respostas são quase sempre consideradas provisórias, ou seja, 'conceitos' constituídos de acordo com diferentes visões e juízos de valor, historicamente situados no tempo e no espaço. Por valores entendemos tudo aquilo que é atribuído por pessoas específicas em situações específicas, de acordo com critérios constituídos segundo seus próprios objetivos. Isso significa que meu 'conceito' do que seja valioso hoje poderá, ao longo do tempo, ser modificado ou transferido para um outro objeto. Da mesma forma, o que julgo valioso pode não ser assim considerado por outros.

Portanto, este trabalho não pretende chegar a um 'suposto' conceito do que seja literatura, mas sim, levantar questões pertinentes ao tema, bem como discutir e analisar, a partir de uma visão crítica, "o que é literatura" com base nos pressupostos de dois autores: Terry Eagleton (2001) em Introdução: O que é literatura ${ }^{1}$ e Jacques Derrida (1992) em This Strange Institution Called Literature: an Interview with Jacques Derrida $^{2}$.

Se falarmos em termos de senso comum, a literatura é definida como uma coleção de obras de valor real e inalterável que se distingue por certas propriedades comuns. Isto nos remete à literatura como uma entidade ou instituição estável e bem definida. Algumas obras são consideradas ficção, outras não. A literatura é então associada a um valor estético, uma escrita altamente valorativa, ao cânone literário por assim dizer, escrita considerada como de valor que resiste à sua própria historicidade. A literatura elitizada com base na literatura maior (culta ou dos 'grandes clássicos') ou menor (de massa ou dos 'best-sellers'). Além do contexto acadêmico, bem como da própria crítica literária que detém o poder para estabelecer "o que é literatura", destacase também o contexto mercadológico ou a indústria cultural que de certa forma controla, discrimina ou privilegia certos 'gêneros'. Essa 'discriminação literária' é facilmente reconhecida ao entrarmos numa livraria, onde percebemos que a arrumação das prateleiras apresenta de um lado romances de autores como Thomas Mann, Jorge Luis Borges, Guimarães Rosa, Machado de Assis, para citar apenas alguns. Do outro lado,

\footnotetext{
${ }^{1}$ Teoria Literária - Uma Introdução. Tradução de Waltensir Dutra. S.Paulo: Martins Fontes, 2001.

2 Jacques Derrida - Acts of Literature. Edited by Derek Attridge. New York and London: Routledge, 1992.
} 
encontraremos os best-sellers como Isaac Asimov, Agatha Christie, Danielle Steel, Dan Brown, Frederick Forsyth, dentre muitos outros (Sodré, 1988).

Perguntamos então, como e por que fazer a diferença entre as supostas literaturas "cultas" e "de massa", se é que isso é possível?

Muniz Sodré $(1988)^{3}$ explica que a literatura assim chamada 'de massa' ou 'de mercado' ou ainda os best-sellers nada mais são que os velhos e muito consumidos 'folhetins', publicados no Brasil nos rodapés dos jornais a partir do século XIX. Sabemos que um best-seller representa uma obra de grande receptividade popular e, que uma obra literária tida como 'culta', por exemplo, pode certamente atingir um público numeroso ou vice-versa. Por outro lado, se pensarmos na questão de autoria, ou seja, que um livro tido como literatura 'de massa' pode tranquilamente ter sido escrito por alguém altamente refinado em termos culturais e, consumido por leitores também tidos como 'de elite' ou 'cultos'. Ainda dentro desta perspectiva, como vamos entender, por exemplo, Oliver Twist de Charles Dickens como literatura 'culta', que faz parte hoje do suposto cânone literário de autores ingleses ou estrangeiros, se originalmente foi publicada como folhetim, tido outrora, portanto, como literatura 'de massa'?

Antonio Candido (1975) ${ }^{4}$ argumenta que existe uma fusão do externo com o interno, do social com o textual no que se refere à obra literária, e que não há como dissociar texto de contexto. $\mathrm{O}$ autor postula a relação dialética que existe entre a obra de arte, por exemplo, e o meio social, cujas forças interagem onde a obra influencia o meio e viceversa e, é por esta razão que a arte, neste caso a literatura, interessa ao sociólogo, pois constitui um sistema simbólico de comunicação inter-humana.

Candido refere-se à literatura como um jogo de relações onde a tríade: obraautor-público representa o sistema de relação inter-humana. A obra só passa a ter sentido ou se tornar realidade quando é aceita ou reconhecida pelo público e, o autor, conseqüentemente, se realiza através desse público que reflete, de certo modo, sua imagem enquanto criador. Por isso, muitos artistas incompreendidos ou desconhecidos em seu tempo, só ‘vivem' na posteridade, quando se define afinal o seu valor. Concluise então que o leitor, como ele entre autor-obra, estabelece a identidade do autor e da obra.

Chartier (1994) em A Ordem dos Livros também discute essa relação da obra com o leitor dizendo que, embora o livro instaure uma ordem, seja ela vinda de seu

\footnotetext{
${ }^{3}$ Best-Seller: A Literatura de Mercado. S.Paulo: Ática, 1988.

${ }^{4}$ Literatura e Sociedade: estudos de teoria e história literária. SP: Nacional, 1975.
} 
interior, de sua decifração e compreensão ou seja ela a ordem exterior, desejada pelo livreiro-editor, o comentador, enfim todos os que pensam em controlar mais de perto a produção de sentido, essa ordem, segundo Chartier (1994), não impede nem anula a liberdade dos leitores. Existe, dessa forma, uma "dialética entre a imposição e a apropriação, entre os limites transgredidos" (CHARTIER, 1994, p. 8) e essa liberdade de ler implica, ainda, nas diferenças de identidades entre os leitores e em sua arte de ler. Isso posto, tentar definir literatura - palavra que provem do latim 'litteratura' e que significa, segundo os dicionários, "a arte de compor escritos artísticos; o exercício da eloqüência e da poesia; conjunto de produções literárias de um país ou de uma época; carreira das letras", não constitui uma tarefa fácil. Contudo, pretendemos com este trabalho percorrer e discutir os caminhos que norteiam os conceitos ou juízos de valor do que seja 'literatura', além de levantar questões relacionadas à sua hierarquia enquanto instituição ideologicamente estabelecida e construída, com base nas visões pós-modernas, porém aparentemente antagônicas, de Eagleton (2001) e de Derrida (1992).

\section{Eagleton e Derrida: discussão e problematização}

Eagleton (2001) discute primeiramente a dificuldade em se definir "o que é literatura", já que o senso comum nos leva a pensar a literatura como uma escrita "imaginativa", ou seja, escrita de ficção ou não-verídica. Por outro lado, ao observarmos as obras tidas como literárias, sejam elas francesas ou inglesas, encontramos toda uma tipologia ou gêneros textuais que vão das tragédias de Shakespeare aos ensaios de Francis Bacon, máximas de la Rochefoucauld, cartas de Mme. de Sevigne à sua filha, sem citar as autobiografias, sermões, etc. Portanto, a distinção entre fato e ficção para definir literatura é altamente questionável.

Segundo o autor, além da dificuldade de distinção entre o que é real e o imaginativo ou criativo, há que se considerar ainda as diferentes maneiras com que alguns autores são lidos, ou a funcionalidade de alguns gêneros, a citar os autores do Gênese que são lidos como fato por alguns e como ficção por outros; o gênero romance (novel) utilizado pelos ingleses tanto para contar fatos ou acontecimentos de ficção.

Eagleton (2001) também chama a nossa atenção para a literatura como peculiaridade de linguagem, a qual se contrapõe à fala comum, citando o crítico russo Roman Jakobson 
que defende a escrita como um "afastamento sistemático" da fala cotidiana e que seria esta a peculiaridade ou materialidade contida no texto literário.

Da mesma forma, para os polêmicos críticos formalistas russos da década de 1920, a literatura constitui uma "forma especial" de linguagem, contrastando-se com a linguagem cotidiana. Esta dita literariedade ou usos especiais da linguagem, presentes nos textos literários representaria, segundo os formalistas russos - leva a certo estranhamento peculiar às obras literárias e por conseqüência a essência desse tipo de texto é colocada em evidência.

O crítico inglês questiona não só a aparente essência da literatura, mas também a ilusão de se acreditar que exista uma única linguagem "normal" ou padrão, pois o que é norma para uns pode representar desvios para outros. $\mathrm{O}$ arcaísmo da linguagem poética de Shakespeare, por exemplo, poderia representar, naquele contexto, a linguagem comum dos apaixonados da época. Ainda, se pensarmos como os formalistas russos, teremos que considerar toda literatura como sendo ligada à questão da estética ou da poesia, uma visão romântica e estilizada da linguagem. E, por último, o problema dos estilos - como julgá-los bons ou ruins? Uma visão extremamente logocêntrica pautada em conceitos absolutistas do certo e do errado.

$\mathrm{O}$ autor discorda do pragmatismo dos formalistas russos e insere o contexto situacional como forma de dar maior significação à linguagem. $\mathrm{O}$ que existe nessa relação, de certa forma dialética, é uma interação da escrita com o leitor, nas palavras dele, não só do que aquilo que "as pessoas fazem com a escrita, como daquilo que a escrita faz com as pessoas" (EAGLETON, 2001, p. 9). Segundo Eagleton, é a forma que o público trata ou considera a literatura que torna um texto 'literário'. É a maneira como lemos o texto e não sua natureza que define o que é literatura. $\mathrm{O}$ autor postula que existem textos que já nascem na condição de literários, outros atingem tal condição, sendo então sua articulação a grande responsável pela maneira ou forma em que um texto é lido, ou seja, um texto pode ser lido pragmaticamente ou poeticamente.

Isso posto, entendemos que é o juízo de valor que determina as particularidades, a literariedade ou não de um texto. Este juízo de valor está estritamente relacionado ao contexto situacional, ou seja, às convicções que vamos construindo através do tempo e do espaço, influenciadas por uma estrutura de valores, de crenças evidentes ou ocultas que são, na maioria das vezes, transitórias, valores transitórios, ideologias.

Ao tratar da literatura como sendo uma agenda 'institucionalizada', com raízes profundas inconscientes, (falsas) crenças, etc, Eagleton (2001) fala das relações de 
poder e da forma como elas interagem com a estrutura social, em termos de reprodução e manutenção de tal poder, remetendo aqui aos conceitos do filósofo francês Michel Foucault $(2000)^{5}$. Segundo Foucault “o poder é uma prática social e, como tal, constituída historicamente" (2000, p. X).

Embora com uma visão um pouco diferenciada, percebo nos argumentos de Eagleton (ibidem), um fio da linha de pensamento muito próximo das reflexões de Jacques Derrida (1992), nas quais postula que a literatura é um lugar estranho onde se permite "dizer tudo", "tudo" no sentido de totalidade e "tudo" no sentido de qualquer coisa, sem restrições, em suas palavras: "the institution which allows to say everything, in every way" (p.36). Na visão de Derrida (1992), ao mesmo tempo que a literatura é vista como uma instituição histórica que cria suas próprias convenções e regras e que, portanto, exerce seu poder, é uma instituição ambígua por quebrar suas próprias regras, rompê-las e desestabilizá-las, devido à função crítica que desempenha. A literatura, segundo Derrida, é um paradoxo em si, pois a mesma liberdade de dizer tudo constitui uma arma política poderosa que pode se deixar neutralizar pela ficção. "Dizer tudo" na perspectiva de Derrida significa poder dizer "qualquer coisa", "de todas as maneiras", e que o espaço da literatura não é somente aquele da ficção instituída, como afirma Eagleton (2001), mas o de uma instituição fictícia que em princípio nos permite dizer tudo. A literatura para o filósofo Derrida (1992) é uma instituição histórica e democrática, pois ao mesmo tempo em que se permite dizer tudo, de libertar-se das leis ou de contradizê-las, deslocá-las, este mesmo poder, de certa forma revolucionário e democrático, pode também tornar-se muito conservador, função esta bastante ambígua e "estranha". A liberdade de dizer tudo, segundo Derrida, é uma arma poderosa que pode ser rapidamente neutralizada como ficção.

Com relação à essencialidade da linguagem literária, Derrida comenta que nem toda literatura é do gênero ficção. Contudo, existe ficção em toda literatura, e é esta funcionalidade que o faz problematizar a "essência" ou a "verdade" do que se convencionou chamar de literatura. Segundo Derrida (1992), é difícil identificar um trabalho literário de forma rigorosa, pois literário não é uma essência natural e nem uma propriedade intrínseca do texto.

Eagleton (2001) ainda compara a instituição da literatura ao Empire State Building, considerado uma das sete maravilhas do mundo. Nas palavras dele "com

\footnotetext{
${ }^{5}$ Microfísica do Poder. Trad. E Org. Roberto Machado. RJ: Graal, 2000
} 
raízes em estruturas mais profundas, de crenças tão evidentes e inabaláveis como o Empire State" (p. 22). O que ele postula, acredito, é que os juízos de valor têm suas raízes em estruturas mais profundas de crenças, tão evidentes e inabaláveis quanto o edifício Empite State. Para Eagleton (2001), a literatura como entende o senso comum é ideologia, ou seja, assim como a religião, guardiã das relações de poder e de controle ideológico, materializando crenças e supostas convicções em práticas e está relacionada com questões de poder social.

As reflexões de Eagleton e Derrida se encontram quanto à questão da "essência" da literatura. Ambos concordam que tal essência é uma ilusão, pois as qualidades do texto literário não são intrínsecas a ele, não estão na escrita em si, mas na forma com que as pessoas se relacionam com ele. A definição de literatura, portanto, depende da maneira que alguém resolve ler e não da natureza do texto. As obras, mesmo as consideradas canônicas, ou sobretudo as canônicas, vão adquirindo significações plurais e móveis que são construídas entre o "encontro de uma proposição com uma recepção" (CHARTIER, 1994, p.9) e que, portanto, não possuem sentido estático, universal e fixo. Por mais que os criadores, as instituições ou os experts tentem fixar um sentido e impor limites à leitura ou ao olhar, não há como evitar o deslocamento e a distorção, a reinvenção da recepção.

Quanto à diferença de pensamento entre os dois críticos, percebo que para Derrida (1992), afirmar que a literatura tem uma função crítica, visão esta apontada por Eagleton (2001) é, de certa forma, estabelecer a ela uma missão, ou talvez, uma única missão, um programa ou um ideal regulador que não compete a ela, e isso a limitaria ou a exterminaria enquanto paradoxo que é, ou seja, de não ter nenhuma função fora dela mesma - uma arma poderosa que tem liberdade de dizer tudo, mas, que ao mesmo tempo se neutraliza como ficção.

\section{Considerações sobre literatura}

Percebe-se por meio dessa discussão sobre "O que é literatura" que o que torna uma obra 'literária' é o leitor que é, por sua vez, ideologicamente formado, construído ou inventado de acordo com seu contexto situacional, contexto este histórico e constituído também via literatura, numa relação dialética entre autor-obra-leitor. A obra se torna uma instituição ao formar seus próprios leitores, atribuindo a eles uma competência que não possuíam anteriormente. Isso pode ocorrer por diversas vias, a 
citar: identificação - autor-estilo-leitor; universidade - seminários, simpósios, currículo, cursos, etc. viabilizando assim sua iterabilidade, ou seja, sua capacidade de duplicação ou de repetição, por meio de diferentes leituras, traduções e re-escrituras. Ao mesmo tempo que a literatura compartilha de certo poder, ela também o excede e o questiona, ficcionalizando-o.

Ainda com relação à invenção ou construção do leitor, concordo com Derrida (1992) quando ele postula que não existe um receptor ou leitor pré-estabelecido como se quer crer, mas sim que o que existe dentro da obra e o que a ela diz respeito são fatores importantes para 'produzir' o leitor. Este leitor é formado, instruído, construído e até manipulado pela obra. O leitor é inventado pela obra literária e, por conseqüência, a obra passa a ser então uma instituição, formando assim seus próprios leitores, dandolhes competência e 'performance'.

Roland Barthes (1982) ao falar de literatura e de autoria, diferencia sentido de significação e diz que literatura é um processo de produção de sentidos, ou seja, de significação (sentidos em movimento). Como sentido ele entende o conteúdo de um sistema de significante ou significado e, como significação, um processo sistemático que une sentido e forma, significante a significado. Embora a perspectiva de Barthes esteja ainda ligada à visão saussuriana de linguagem (linguagem como um sistema limitado, constituído por significante e significado), suas reflexões são muito atuais quando tratam da relação sentido e literatura. Ele postula que o sentido de um texto ou de uma obra não se faz por si só. Segundo ele, o autor apenas presume sentidos ou formas que vão sendo preenchidas ao longo do tempo pelos leitores que se deparam com a obra. Barthes (1982, p. 124) comenta que "se as palavras tivessem somente um sentido, o do dicionário, se uma segunda língua não viesse perturbar e liberar as 'certezas da linguagem', não haveria literatura”. Portanto, a literatura representa uma significação em movimento ou aquilo que se diz dela e isso, obviamente, inclui o texto literário que, apesar de funcionar como um significante através do tempo, significando 'nada' por se tratar de algo evanescente ou vazio, seu 'ser' está na significação e não em seus supostos significados (ibidem, p.70). Essa idéia de texto nos remete ao que

Chartier (1994, p. 9) comenta sobre o livro como forma em movimento, dizendo que por ordem do livro entende-se, além de outros fatores, que "os sentidos atribuídos às suas formas e aos seus motivos dependem das competências ou das expectativas dos diferentes públicos que delas se apropriam”. 
Numa linha próxima de pensamento, Hirsh (1967, citado por EAGLETON, 2001, p. 92) também diferencia significação de sentido, dizendo que o sentido emana do autor enquanto que as significações são atribuídas pelo leitor e variam ao longo da história. Para Hirsch (ibidem) uma obra literária pode significar diferentes coisas para diferentes pessoas.

Eagleton (2001, p. 98) cita Gadamer (em Verdade e Método) para defender que significados vão sendo extraídos de acordo com o contexto histórico pelo qual uma obra passa, significados estes que podem nunca terem sido imaginados pelo autor ou pelo próprio público contemporâneo dele. Portanto, a obra literária nada mais é do que um “diálogo com sua própria história” (EAGLETON, 2001, p. 98). Não há literatura sem leitor.

Abro aqui um parêntese para inserir o papel que a tradução tem como "sobrevida da obra literária", pois as grandes obras, como sabemos, se perpetuam através de suas traduções, ou seja, sua sobrevida e iterabilidade se garante, em grande parte, por meio da tradução que contribui para esse diálogo da obra com sua história. Da mesma forma que a língua representa um campo de forças sociais que nos modela, a obra literária também é regida por certas forças, a exemplo do próprio meio acadêmico. O professor, segundo Eagleton (2001), representa a instituição acadêmica, excluindo certas leituras e permitindo outras. Na tentativa de legitimar leituras pré-estabelecidas, ele limita a competência do aluno-leitor de 'interpretar' o texto. O significado fixo, bem como a suposta intenção do autor são formas de fixar a obra literária e contribuir para sua canonização. Assim, é a 'instituição literária' que determina os limites e a aceitação dessas leituras, a citar a crítica literária e a indústria cultural por um lado e a tradução, por outro.

Para concluir, concordo com Derrida ao entender que literatura como instituição que é, com sua dita singularidade ou literariedade, depende da contra-assinatura do leitor. Um texto pede para ser lido ou traduzido para sua própria sobrevivência, correndo o risco de ser, paradoxalmente, 'respeitado' e 'traído' segundo os conceitos de singularidade ou essencialidade, pois o essencial não está dentro do texto, mas sim fora dele.

Contudo, há que se mencionar que essa dificuldade em se 'definir' literatura não acarreta nenhum problema quanto à sua funcionalidade, ou seja, a existência dela independe de problematizações, pois a literatura e a crítica literária não acontecem por decreto, mas sim por sua própria funcionalidade cultural, social e econômica. 


\section{Referências}

BARTHES, Roland. Crítica e Verdade. Trad. De Geraldo Gerson de Souza. S.Paulo: Perspectiva, 1982.

CANDIDO, Antonio. Literatura e Sociedade: estudos de teoria e história literária. SP: Nacional, 1975.

CHARTIER, Roger. A Ordem do Livro. Trad. de Mary del Priore. Brasília: UnB., 1994.

EAGLETON, Terry. Teoria Literária - Uma Introdução. Tradução de Waltensir Dutra.

S.Paulo: Martins Fontes, 2001.

DERRIDA, Jacques. Acts of Literature. This Strange Institution Called Literature. Edited by Derek Attridge. New York and London: Routledge, 1992.

FOUCAULT, Michel. Microfísica do Poder. Trad. E Org. Roberto Machado. RJ: Graal, 2000 .

SODRÉ, Muniz. Best-Seller: A Literatura de Mercado. S.Paulo: Ática, 1988. 